DOI: $\underline{\text { https://doi.org/10.24867/12IH03Saponjic }}$

\title{
SISTEM ZA KONTROLU NAPLATE PARKIRANJA NA ZATVORENIM PARKIRALIŠTIMA
}

\section{PARKING CONTROL SY STEM FOR CLOSED PARKING LOTS}

\author{
Milan Šaponjić, Fakultet tehničkih nauka, Novi Sad
}

\section{Oblast - Napredne inženjerske tehnologije}

Kratak sadržaj - U okviru ovog rada opisan je sistem koji služi za kontrolu naplate parkiranja na zatvorenim parkiralištima.

Ključne reči: Industrijski računar, prepoznavanje karaktera, kontrola naplate parkiranja

Abstract - The system for control of the payment in closed parking lots is described In this paper

Keywords: Industrial computer, character recognition, parking payment

\section{UVOD}

Postoje različiti načini naplate parkiranja i provere naplate parkiranja [1-6]. U ovom radu opisan je sistem za kontrolu naplate parkiranja na zatvorenim parkiralištima. Najvažnije deo ovog sistema predstavlja prepoznavanje registarskih oznaka vozila korišćenjem kamere. U slučaju da je registarska oznaka prepoznata, započinje provera da li je plaćeno korišćenje parking prostora.

U slučaju da i nakon 15 minuta od prepoznavanja ulaska na parking prostor, nije plaćeno njegovo korišćenje, šalje se obaveštenje kontroloru koji treba da napiše kaznu (doplatnu kartu) vozaču.

Potreba za ovim sistemom nastala je kako bi se vozači stimulisali da plaćaju korišćenje parking prostora za svoje vozilo. Takođe, na ovaj način dobijamo sistem koji olakšava posao kontroloru. Njegov posao više nije da proveri da li je plaćeno korišćenje parking prostora za svako vozilo, već samo ona za koje mu sistem pošalje obaveštenje.

Ovaj rad je podeljen na sedam poglavlja. U drugom poglavlju je opisan izbor industrijskog računara, koji komunicira sa perifernim uređajima (kamerom za prepoznavanje registarskih oznaka, displejom za prikazivanje broja slobodnih mesta na parkiralištu i displejom za prikaz obaveštenja o plaćenosti parkinga) i serverom.

U trećem poglavlju, akcenat je dat na izbor odgovarajuće kamere i softvera za prepoznavanje registarskih oznaka. Ovaj podatak (registarska oznaka vozila) se prosleđuje industrijskom računaru.

\footnotetext{
NAPOMENA:

Ovaj rad proistekao je iz master rada čiji mentor je bio dr Stevan Stankovski, red. prof.
}

U četvrtom poglavlju opisane su teorijske osnove rada informacionih displeja, koji služe da vozaču pruže informaciju o zauzetosti parkirališta i informaciju o izvršenoj usluzi plaćanja korišćenog parking prostora.

U petom poglavlju opisan je jedan realizovan sistem za kontrolu naplate parkiranja na parkiralištima $\mathrm{u}$ gradu Paraćinu.

U šestom poglavlju izneta su zaključna razmatranja. Sedmo poglavlje sadrži spisak korištene literature.

\section{INDUSTRIJSKI RAČUNAR}

Industrijski računari su uređaji namenjeni za automatizaciju mašina koje se koriste $\mathrm{u}$ industrijskim pogonima (slika 1) [7]. Zbog svoje konstrukcije mogu da trpe visoke temperature, skokove napona u sistemu, što može naneti ozbiljnu štetu komercijalno dostupnom računaru. Zbog toga industrijski računari imaju unutrašnje komponente napravljene od legiranih materijala koji mogu da podnesu visoke temperature $i$ vibracije. Industrijski računari su dizajnirani posebno za upotrebu u oblastima kao što su industrijska automatizacija ili rudarski procesi gde su prašina i strani ostaci često uobičajeni pratilac. Savremeni industrijski računari, omogućuju da se koriste računarske tehnologije, poput računarstva na ivici, Interneta stvari, veštačke inteligencije, dronova [8-13].

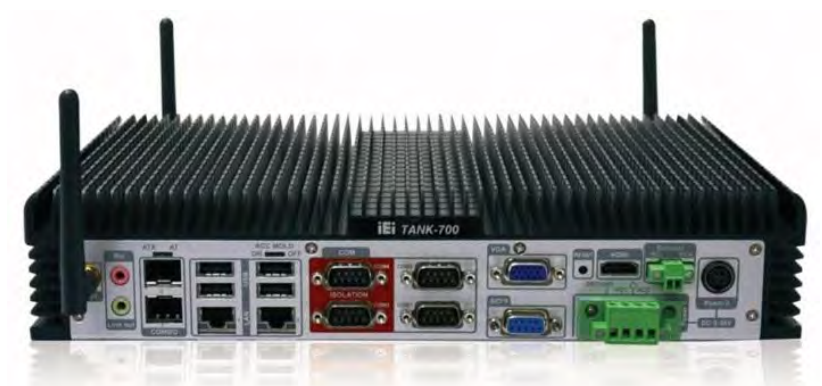

Slika 1. Industrijski računar

(https://mehatronika.gomodesign.rs/industrijski-racunariistine-i-zablude/)

U projektu je korišćen industrijski računar kompanije IEI Integration Corp, model WAFER-AL (slika 2) [14-15]. Serija WAFER-AL je 3,5-inčni računar sa jednom pločom. Ima ugrađeni Intel $14 \mathrm{~nm}$ Pentium ili Celeron procesor i podržava jedan 204-pinski 1867/1600 MHz jednokanalni DDR3 niskonapanski (DDR3L) SDRAM SO-DIMM slot sa do 8,0 GB memorije. Serija WAFERAL uključuje jedan DP++ konektor, jedan VGA konektor 
i jedan 18- /24-bitni LVDS konektor za trostruki nezavisni prikaz. Dva konektora RJ-45 GbE obezbeđuju sistemu glatke veze sa spoljnim LAN-om. Proširenje I/O uključuju jedan PCle Mini slot koji podržava mSATA module, jedan PCle Mini slot sa držačem SIM kartice, dva USB 3.2 prve generacije konektora na zadnjoj ploči, četiri USB 2.0 konektori pomoću pin zaglavlja i dva SATA konektora. Serijski uređaj povezanost pružaju dva unutrašnja RS-232 konektora i dva unutrašnja RS232/422/485 konektora.

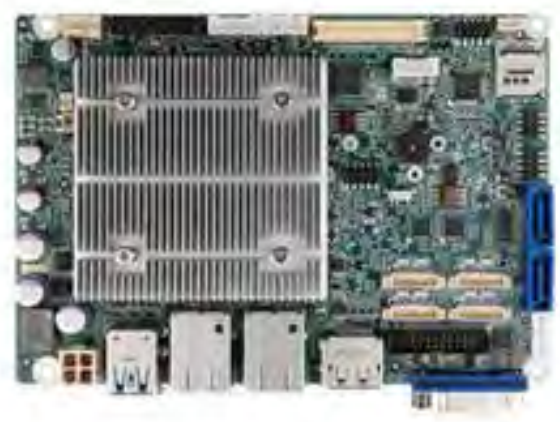

Slika 2. WAFER-AL industrijski računar

(https://www.ieiworld.com/en/product/model.php?II=575)

Pored gore navedenih karakteristika dodatno se ističe pin zaglavlje na koje je moguće povezati digitalne signale naponskog nivoa od $0 \mathrm{~V}$ do $5 \mathrm{~V}$, koji se u projektu koriste za prikupljanje informacije o ulasku/izlasku vozila sa parkinga. Pored hardverskog, tu je i finansijski benefit, jer je izbegnuto korišćenje programabilnog logičkog kontrolera, koja bi obavljao tu funkciju.

\section{KAMERA ZA PREPOZNAVANJE REGISTARSKE OZNAKE}

Automatsko prepoznavanje registarske oznake vozila (ANPR) je tehnologija koja koristi optičko prepoznavanje karaktera na slikama, kao što je prikazano na slici 3. Ovu tehnologiju koriste policijske snage širom sveta za potrebe sprovođenja zakona, proverom da li je vozilo registrovano ili ukradeno. Takođe se koristi za elektronsko naplaćivanje putarina na putevima, kao i za automatsko otvaranje rampe na parkingu.

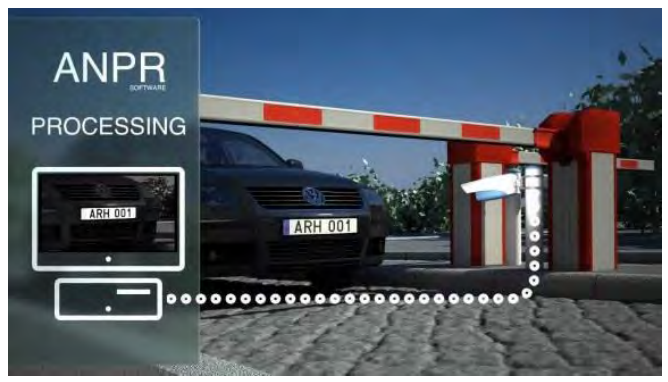

Slika 3. Sistem sa ANPR kamerom

(https://www.fierceelectronics.com/components/anprsystem-market-showing-good-potential)

Automatsko prepoznavanje registarskih oznaka vozila može se koristiti za čuvanje slika snimljenih kamerom, kao i karaktera sa registarskih oznaka. Uz dodatnu konfiguraciju moguće je u bazi podataka sačuvati fotografiju vozača. Sistem obično koristi infracrveno osvetljenje, kako bi mogao da slika u bilo koje doba dana ili noći. Automatsko prepoznavanje registarskih oznaka mora uzeti u obzir varijacije registarskih oznaka različitih država.

Pitanje privatnosti izazvalo je zabrinutost oko automatskog prepoznavanja registarskih oznaka. Neke od zabrinutosti u vezi ovog sistema su vladino praćenje kretanja građana, pogrešne identifikacije, visoka stopa greške i povećane državne potrošnje. Kritičari su opisani kao oblik masovnog nadzora.

Za potrebe projekta je izabrana kamera proizvođača HikVision, oznake DS-2CD4A26FWD-IZHS (slika 4) [16]. Ovaj tip kamere je u stanju da snima fotografije vozila i prepoznajte registarsku oznaku vozila pri slabom osvetljenju okruženja. Kamera je dostupna u objektivima od 2,8-12 mm i 8-32 mm opcije i karakteriše stopa registarske oznake prepoznavanja do 95 procenata.

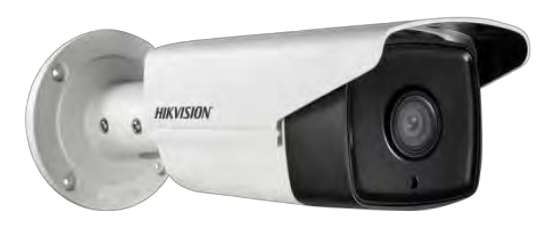

Slika 4. HickVision ANPR kamera

(https://www.alarmtec.co.za/hikvision-networkcameras/2cd4a26fwd-izs-p-2324.html)

Stepen zaštite kamere je IP67, što znači da je poseduje vodootporno kućište, koje je otporno na jake pljuskove. Prednost kamere je komunikacija i napajanje preko UTP kabla, koristeći POE port na switch-u. Gabaritne dimenzije kamere su 103x100x312 mm.

Za potrebe projekta su postavljene dve kamere koje snimaju dva ulaza/izlaza. Pored svih prednosti koje poseduje kamera mora se voditi računa o poziciji postavljanja kamere.

\section{INFORMACIONI DISPLEJI}

Prilikom ulaska/izlaska sa parkinga, vozači mogu da se informišu na četiri informaciona displeja, po dva na svakom od ulaza/izlaza na parking (slika 5). Prvi informacioni displej služi za prikazivanje brojčane informacione poruke o broju mesta na parkingu dok drugi pruža informaciju vozaču o plaćenosti parkinga, prilikom izlaska

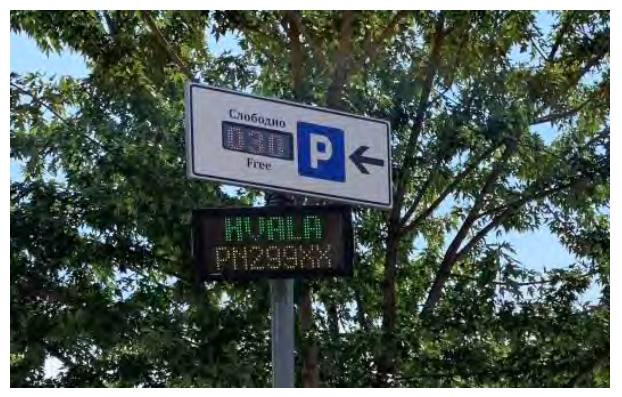

Slika 5. Informacioni displeji 
Informacija o broju mesta se na displeju kreira uključivanjem određenog skupa jednobojnih LED dioda [17]. Dioda koja emituje svetlost (LED) je poluprovodnički izvor svetlosti koji emituje svetlost kada kroz nju teče struja. Elektroni u poluprovodniku se rekombinuju sa elektronskim rupama, oslobađajući energiju u obliku fotona. Boja svetlosti (koja odgovara energiji fotona) određena je energijom potrebnom da elektroni pređu zaporni opseg poluprovodnika. Bela svetlost se dobija korišćenjem više poluprovodnika ili sloja fosfora koji emituje svetlost na poluprovodničkom uređaju.

Najstarije LED diode su se 1962. godine pojavile kao praktične elektronske komponente, a zračile su infracrvenom (IR) svetlošću niskog intenziteta. Infracrvene LED se koriste $\mathrm{u}$ daljinskim upravljačkim krugovima, poput onih koji se koriste sa širokim spektrom potrošačke elektronike. Prve LED diode vidljive svetlosti bile su slabog intenziteta i ograničene na crvenu. Moderne LED diode dostupne su na vidljivim, ultraljubičastim (UV) i infracrvenim talasnim dužinama, sa velikom svetlošću.

Informacija o plaćenosti parkinga se na displeju kreira uključivanjem određenog skupa RGB LED dioda [18] RGB LED dioda je u osnovi LED paket koji može proizvesti gotovo bilo koju boju. Može se koristiti u različitim aplikacijama kao što su osvetljenje za spoljnu dekoraciju, dizajni osvetljenja pozornica, osvetljenje za uređenje doma, LED matrični displej i još mnogo toga.

RGB LED diode imaju tri unutrašnje LED diode (crvenu, zelenu i plavu) koje se mogu kombinovati da bi se proizvele gotovo sve izlazne boje. Da bismo proizveli različite vrste boja, moramo da podesimo intenzitet svake unutrašnje LED diode i kombinujemo tri izlaza u boji. U ovom uputstvu ćemo koristiti PWM za podešavanje intenziteta crvene, zelene i plave LED diode pojedinačno, a trik je ovde da će naše oči videti kombinaciju boja, umesto pojedinačnih boja, jer su LED diode veoma blizu jedna drugoj iznutra.

Kao što je ranije pomenuto, RGB LED diode imaju tri LED diode u sebi i obično ove tri unutrašnje LED diode imaju zajedničku anodu ili zajedničku katodu, posebno u paketu kroz rupe. Dakle, u osnovi možemo kategorizovati RGB LED kao uobičajenu anodu ili zajedničku vrstu katode, baš kao na sedmosegmentnim displejima.

Oba tipa displeja, proizvela je firma Novatronic iz Novog Sada.

\section{OPIS RADA SISTEMA ZA PREPOZNAVANJE REGISTARKE OZNAKE}

U cilju bolje i efikasnije naplate parkiranja na javnom zatvorenom parkiralištu, postavljen je sistem koji će omogućiti identifikaciju svih vozila koja ulaze/izlaze na tom parkiralištu. $\mathrm{Na}$ oba ulaza/izlaza na parkiralište postavljene su kamere koja prepoznaju registarsku oznaku vozila i pri ulasku i pri izlasku sa parkinga (slika 6 i slika 7).

Prilikom ulaska vozila na parking, kamera prepoznaje registarsku oznaku vozila i taj se podatak smešta u bazu podataka (lokalnu i na serveru), zajedno sa vremenom ulaska i ulaznom fotografijom vozila. Slika vozila sadrži datum i vreme ulaska. Prilikom izlaska vozila sa parkinga, kamera opet vrši prepoznavanje registarske oznake vozila i na osnovu toga se vrši dodavanje vremena izlaska u bazi izlaska vozila izlazne fotografije vozila.

Softver na serveru na kome se čuvaju podaci o registarskim oznakama vozila i slike ulaznih i izlaznih vozila imaju opcije pretrage po registarskoj oznaci i to na takav način da kada operater unese registarsku oznaku dobije odgovarajuću sliku vezanu za tu oznaku.

Nakon 15 minuta od ulaska vozila na parkiralište, na serveru se vrši provera da li je vozilo napustilo parking. Ukoliko je informacija negativna, proverava se da li je plaćeno parkiranje za datu registarsku oznaku. Softver vrši konekciju sa bazom podatka na parkomatima i SMS serveru i očitanu (OCR) registarsku tablicu upoređuje sa izvršenim uplatama od strane korisnika parkinga. Ako se prilikom provere utvrdi da parkiranje nije plaćeno, šalje se obaveštenje parking kontroloru za pisanje kazne.

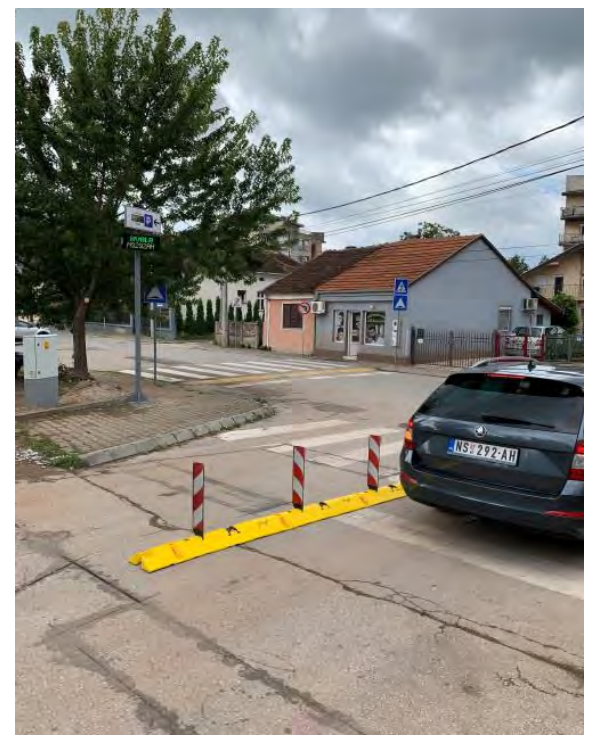

Slika 6. Prikaz funkcionisanja sistema prilikom izlaska vozila

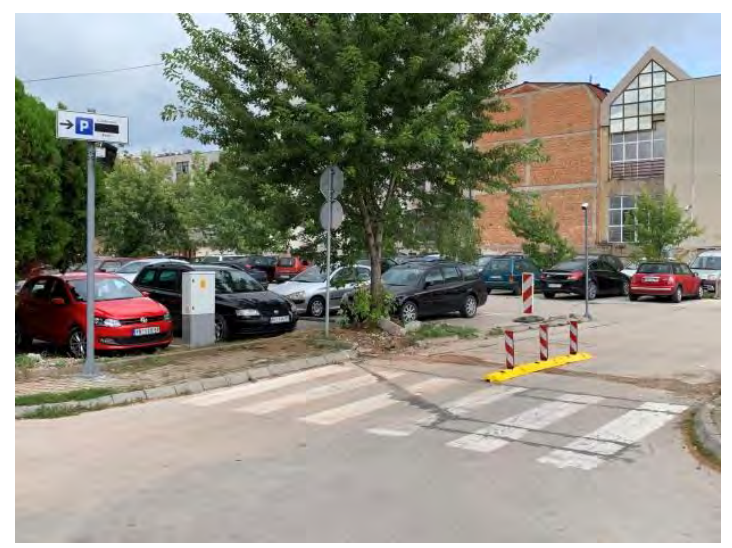

Slika 7. Izgled celokupnog sistema

$\mathrm{Na}$ oba izlaza sa parkirališta se postavljaju informacioni displeji. Prilikom izlaska vozila sa parkinga, ako nije plaćeno parkiranje za dato vozilo, na izlaznom displeju se ispisuje poruka crvenim karakterima (tekst: NISTE PLATILI PARKING), a ako je plaćeno parkiranje, ispisuje se poruka zelenim karakterima (tekst: HVALA). 
Serveru se pristupa preko standardnih veb pretraživača, uz odgovarajuće korisničko ime i lozinku i moguće je posmatrati situacije u realnom vremenu. Veza između registarske oznake vozila je kompatabilna sa sistemom naplate parking prostora $u$ gradu Paraćinu.

Nakon ulaska vozila na parking, dekrementuje se vrednost na ulaznom displeju, koja predstavlja broj slobodnih mesta na parkingu. Utvrđivanje smera kretanja vozila prilikom ulaska/izlaska na parking se vrši pomoću indukcionih petlji postavljenih $\mathrm{u}$ asfalt. Nakon izlaska vozila sa parkinga inkrementuje se vrednost broja slobodnih mesta. U aplikaciji kojoj pristupaju operateri iz parking servisa je omogućena korekcija prikaza broja slobodnih mesta.

\section{ZAKLJUČAK}

Nakon implementacije sistema, u probnom periodu je potvrđeno da sistem uspešno prepoznaje registarske oznake u 92\% slučajeva. Jedan od izazova je bio podesiti odgovarajući ugao kamere kako bi mogla da fotografiše registarsku oznaku vozila u obe kolovozne trake. Sama pozicija kamera utiče na manji broj uspešnosti prepoznanja u odnosu na specifikaciju korišćene kamere koja iznosi $95 \%$.

Razvijeni sistem može da se uspešno primeni i u sličnim okruženjima, odnosno svim onim okruženima gde se mogu kamere postaviti da se prepoznavanje registarskih oznaka vozila može ostvariti na čitavoj širini kolovozne trake. I pored toga što uspešnog prepoznavanja registarskih oznaka ne iznosi $100 \%$, ovakvi sistemi su od ogromne pomoći u procesima prepoznavanja slučajeva kada se ne uradi plaćanje korišćenja parking prostora.

$\mathrm{U}$ toku realizacije ovog master rada imao sam priliku da iskusim kako funkcioniše timski rad. Dobijeno iskustvo će mi sigurno pomoći u realizaciji novih projekata.

\section{LITERATURA}

[1] Stankovski, S.; Ostojić, G.; Tarjan, L. ; Stanojević, M. \& Babić, M. (2019) Challenges of IoT payments in smart services, 2019, 30th DAAAM International Symposium on Intelligent Manufacturing and Automation, DAAAM 2019, Zadar, Croatia, 23-26 October 2019, Annals of DAAAM and Proceedings of the International DAAAM SymposiumVolume 30, Issue 1, 2019, pp 4-9

[2] Tejić, B.; Tegeltija, S.; Horvat, S.; Nićin, M.; Stanojević, M. \& Babić, M. (2019). Payment Methods in Vending Machiness, Journal of Mechatronics, Automation and Identification Technology, Vol. 4, No. 3, 2019, pp. 20-25, ISSN 2466-3603

[3] Ostojic, G.; Stankovski, S.; Lazarevic, M. \& Jovanovic, V. (2017). Implementation of RFID technology in parking lot access control system, 2007 1st Annual RFID Eurasia, 2007, pp. 1-5

[4] Baranovski, I.; Stankovski, S.; Ostojic, G. \& Horvat, S. (2020). Support for Self-service Automated Parking Systems, Proceedings of the 19th International Symposium INFOTEH-JAHORINA (INFOTEH), East Sarajevo, Bosnia and Herzegovina, 2020, pp. 1-5, doi: 10.1109/INFOTEH48170.2020.9066319.
[5] Baranovski, I.; Stankovski, S. ; Ostojic, G., Horvat, S. \& Tegeltija, S. (2020). Augmented reality support for self-service automated systems, Journal of Graphic Engineering and Design, 2020, 11(1), pp. 63-68

[6] Stankovski, S.; Ostojić, G. \& Zhang, X. (2016). Influence of Industrial Internet of Things on Mechatronics, Journal of Mechatronics, Automation and Identification Technology, Vol. 1, No. 1, March 2016, pp. 1-6, ISSN 2466-3603

[7] https://en.wikipedia.org/wiki/Industrial_PC, pristupljeno 1.10.2020.

[8] Stankovski, S.; Ostojić, G.; Zhang, X.; Baranovski, I.; Tegeltija, S. \& Horvat, S. (2019). Mechatronics, Identification Tehnology, Industry 4.0 and Education, Proceedings of the 18th INFOTEHJAHORINA 2019,

[9] Stankovski, S.; Ostojic, G.; Saponjic, M.; Stanojevic, M. \& Babic, M. (2020). Using micro/mini $\mathrm{PLC} / \mathrm{PAC}$ in the Edge Computing Architecture, Proceedings of the 19th International Symposium INFOTEH-JAHORINA (INFOTEH), East Sarajevo, Bosnia and Herzegovina, 2020, pp. 1-4,

[10] Stankovski, S.; Ostojic, G.; Baranovski, I.; Babic, M. \& Stanojevic, M.. (2020). The Impact of Edge Computing on Industrial Automation, Proceedings of the 19th International Symposium INFOTEH-JAHORINA (INFOTEH), East Sarajevo, Bosnia and Herzegovina, 2020, pp. 1-4, doi: 10.1109/INFOTEH48170.2020.9066341

[11] Nemet, S.; Ostojic, G.; Kukolj, D.; Stankovski, S.; \& Jovanovic, D. (2019). Feature Selection Using Combined Particle Swarm Optimization and Artificial Neural Network Approach, Journal of Mechatronics, Automation and Identification Technology, Vol. 4, No. 4, 2019, pp. 7-11, ISSN 2466-3603

[12] Ostojic, G.; Stankovski, S.; Tejić, B.; Đukić, N.; Tegeltija, S. (2015). Design, control and application of quadcopter, International Journal of Industrial Engineering and Management (IJIEM), Vol. 6 No 1, March 2015, pp. 43-48, ISSN 2217-2661

[13] M. Jocković, Z. Ognjanović, S. Stankovski, Veštačka inteligencija: inteligentne mašine i sistemi, Krug, Beograd, 1988.

[14] https://www.ieiworld.com/en/product/model.php

?II=575 Data Sheet IM12-04NPS-ZC1 6011983 en

[15] WAFER-AL_UMN_v1.03 User Manual

[16] QuickStartGuideofDS2CD4A26FWD(IZHS)(LZ

S)P

[17] https://en.wikipedia.org/wiki/Light-

emitting_diodePristupljeno 4.10.2020.

[18] https://www.circuitbread.com/tutorials/how-rgbleds-work-and-how-to-control-color, Pristupljeno 5.10.2020.

\section{Kratka biografija:}

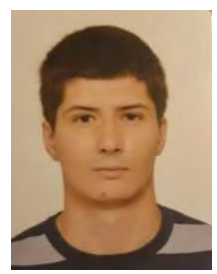

Milan Šaponjić rođen je u Užicu 1995. godine. Osnovnu i srednju školu završio je u Užicu. Diplomirao je 2019. godine na Fakultetu tehničkih nauka u Novom Sadu. 